\title{
Designing Our Future Bio-Materiality
}

\author{
Carole Collet, Professor in Design For Sustainable Futures \\ Director, Design \& Living Systems Lab \\ Central Saint Martins University of the Arts \\ 1 Granary Square, \\ London N1C4AA \\ United Kingdom \\ c.collet@csm.arts.ac.uk \\ $0044(0) 2075147140$
}

\begin{abstract}
A new road map for design is emerging out of interdisciplinary research across biology and design. Whilst in the second part of the 20th century, the emergence of the digital realm altered and radically challenged conventional design and manufacturing processes, the beginning of the 21 st century marks a strong shift towards the amalgamation of the binary code (1s and 0s) with biological systems. With advances in synthetic biology, we can now 'biofabricate' like Nature does. By tinkering and altering the DNA code or the environment of growth of living organisms, we can effectively 'design' and grow new biomaterials. The role of design is shifting from working with inanimate matter such as plastic and metals to making with animate living entities such as mycelium, yeast and bacteria. This paradigm shift promises to open up new possibilities for biofabricating future intelligent materials as well as for engaging with new sustainable processes. This paper examines strategies and tools for designing with living systems and proposes a framework for design to engage with our future bio-materiality. From biofabrication experiments to synthetic biology propositions, the paper will investigate a series of design artifacts that explores strategies such as co-designing with natural organisms or actuating a new synthetic nature and develop a critique of how biodesign can help shifting towards the crafting of a future sustainable intelligent bio-materiality.
\end{abstract}

Keywords: biodesign, biofabrication, bio-materiality, sustainability

\section{Introduction}

We have evolved out of our ability to harvest, control, or cooperate with natural systems. Simply looking at the history of food, we can witness a long established relationship with microbial invisible organisms. Fermenting grapes, brewing beer, churning cheese or baking bread are all testimonies to our successful long term cooperation with yeast and microbes. Only, we rarely think of it this way. Journalist Michael Pollan, when writing about our natural history of transformation, references a conversation with food chemist Bruce German. He points out that we would not survive on simply flour and water, but our chances would increase when eating bread. As the yeast naturally present in the wheat is activated by water, a whole new level of nutrients and flavours blossoms Polan | (2013). Knowing to trigger and control the life and work of the yeast is the secret of bakers. But now, the ability to cooperate with a range of simple living organisms such as yeast is becoming part of the craft of designers. In the past decade, a growing number of architects and designers have begun to explore new biofabrication techniques resonant of our food transformation processes and husbandry techniques. Cooperating with slime moulds, 
cultivating mycelium and designing habitats for algal networks are being amalgamated as alternative sustainable propositions to the more conventional realm of design. The intersection of biology and design has now opened up a new landscape for the design and biofabrication of materials, artifacts, and architectural systems.

Section 2 of this paper will position this emerging new biodesign landscape within a sustainable context. The third section will argue for the ecological advantage of Nature's ability to biofabricate materials, the fourth will propose a framework for designing with living systems as a means to develop a critical and ethical stance when working with biological tools. The fifth section will evaluate strategies for co-designing with living organisms, and the final section will examine the impact of synthetic biology onto a possible future programmable and sustainable bio-materiality.

\section{Biodesign and Sustainability in Context}

Rather than evolving to adapt to our natural habitat, we, humans have technologically transformed our environment to suit our evolution. By doing so, we have shifted our perception of Nature throughout history. Ranging from the Greek hylozoist philosophy that imbued living qualities to matter, 6th Century B.C, to Descartes' understanding of life as a mechanistic process in the 17thCentury; we have constructed various lenses to make sense of the world around us Capra and Luisi | (2014). And whilst Cartesian and Newtonian rationales prevailed in the 20th century, the emergence of systems thinking, the first notions of ecosystems and the supremacy of life sciences over physics, have began to seed the onset of a new era. 'The Zeitgeist of the early twenty-first century is being shaped by a profound change of paradigms, characterized by a shift of metaphors from the world as a machine to the world as a network' Capra and Luisi | (2014:12). The $21^{\text {st }}$ Century marks the rise of a sustainable consciousness, and as we begin to unravel the environmental consequences of our economic growth, we are faced with the legacy of a mechanistic perception of Nature. Nobel Laureate Paul Crutzen argues that as a species, we begun to alter the planet's geophysical forces, unbalance its ecosystem and initiate a climate change when we begun to industrialise our means of production. 'One of the three or four most decisive transitions in the history of humankind, potentially of similar importance in the history of the Earth itself, was the onset of industrialization' Crutzen | (2007: 616).

The acknowledgment of this Anthropocene epoch, as Crutzen defines it, sets the scene for a new critical context for design and its related industries. With the birth of the industrial revolution, followed the emergence of the design profession, which developped at a time when natural resources simply represented a means to pursue rapid economic growth and wealth. In his seminal book, Design For The Real World, Papanek referred to design as a harmful profession: "...by creating whole new species of permanent garbage to clutter up the landscape, and by choosing materials and processes that pollute the air we breathe, designers have become a dangerous breed" Papanek | (1985: 4). Although thirty years old, this statement still resonates today. However the role and responsibility of designers is evolving positively with a growing engagement towards more sustainable practices. Shifting from a linear to a circular economy, applying 'cradle to cradle' design principles Braungart and MacDonaugh | (2009) and sourcing renewable sustainable materials now belong to the realm of the designer.

Yet, designing and making new products, by definition often implies destroying natural resources. 'It is not just a solitary tree that gets destroyed to become a table, but a home 
to birds and mammals, to insects and fungi, and other plant species.' Tonkinwise | (2014: 201). Whether we use wood, plastic, metal, or cotton, all materials we specify originate from the planet and their extraction, transformation or production has environmental consequences. Today, the world's population has reached nearly 7.6 billion, 'implying that the world has added approximately one billion inhabitants over the last twe/ve years' United Nations | (2017: 1). This rapid population growth entails a sudden increase in consumption and a use of our natural resources greater than ever. We are currently consuming our natural resources faster than they can regenerate and are operating in overshoot mode. 'Humanity currently needs the regenerative capacity of 1.6 Earths to provide the goods and services we use each year. 'WWF | (2016: 13). We need to explore alternative options for future design and manufacture which do not continue to deplete our natural resources faster than they can renew themselves. 'We urgently need to reconnect our societies, and thereby our economy, to the biosphere. In the globalized phase of environmental change, where human societies in the Anthopocene are hitting the ceiling of Earth's biophysical, ecological and resource capacities, we need to recognise that future prosperity depends on our capacity to stay within the planetary boundaries.' Wijkman and Rockstrom | (2012:184). The recent emergence of biodesign practices is encouraging the development of a design process that incorporates biological principles (biomimicry) or biological tools inspired by how Nature fabricates. This new practice can contribute to a shift towards more sustainable design and manufacture principles and the section below will argue the benefit of mimicking Nature's operational mode.

\section{Decoding the Biological Advantage}

What can we learn from Nature that can inform more resilient and sustainable design and manufacturing systems? Biomimicry is an approach that emulates successful strategies found in Nature to inspire new sustainable innovations and is referenced by researchers, scientists, designers and architects alike. 'Life can't put its factory on the edge of town; it has to live where it works. As a result, nature's first trick of the trade is that nature manufactures its materials under life friendly conditions, in water, at room temperature, without harsh chemicals or high pressures' Benyus | (1997: 97). Let's take the example of glass making. We manufacture glass by melting sand and other compounds at temperatures above $1000^{\circ} \mathrm{C}$ for several hours, whilst a diatom can make a glass-like shell in a couple hours, at ambient temperature by transforming traces of silica present in water, using a set of proteins and enzymes. Diatoms are unicellular microscopic algae that live in aquatic environments and grow many different types of architecture as seen in Figure 1. 


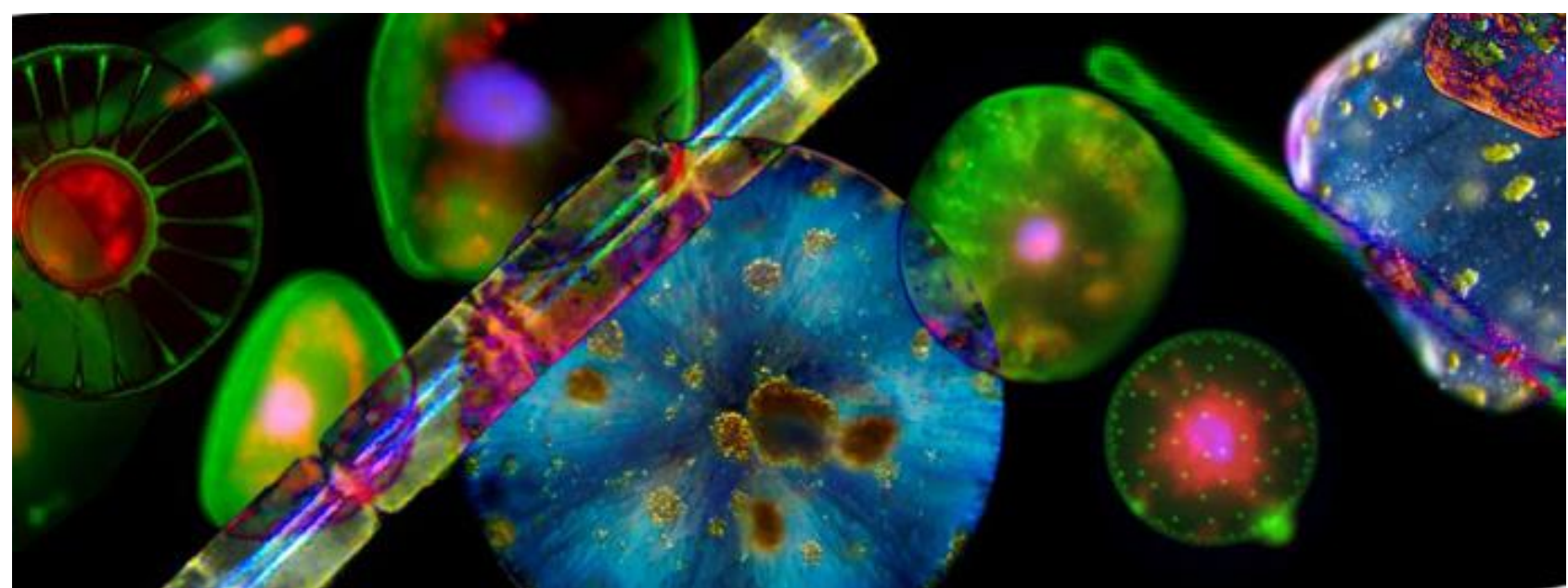

Figure 1: Diatoms. (c) Chris Bowler and Angela Falciatore, Christian Sardet, Atsuko Tanaka. Environmental and Evolutionary Genomics Section, Institut de Biologie de l'Ecole Normale Supérieure, CNRS, France.

To be able to grow glass-like structures locally and at ambient temperature, like diatoms, would radically reduce our energy consumption and $\mathrm{CO}_{2}$ emissions. And eventhough in 2008 , researchers in green chemistry developed a process that imitates the diatoms glass making natural chemistry applicable at micro scale for biomedical purpose Livage and Coradin | (2008), we are far from being able to replicate this model at industrial scale. So far, the biological model for making glass-like material is far superior to the man-made approach in terms of sustainable impact, energy consumption and CO2 emission.

However, other examples of mimicking Nature are proving to be much more easily transferable. By learning from how a thermite mound is engineered to create a micro climate, architect Mick Pierce in collaboration with Arup engineers designed the Eastgate Centre in Zimbabwe, a building that can optimize its natural cooling capacity. Studying a desert beetle can teach us how to harvest water from morning dew, a strategy explored by architect Michael Pawlyn who argues, 'you could look at nature as being like a catalog of products, and all of those have benefited from a 3.8 billion year research and development period. And given that level of investment, it makes sense to use it.' Pawlyn | (2011). Designer Guillian Graves and bio-engineer Michka Melo took that approach to create Nautile, a kettle whose design was inspired by a range of living organisms (the Nautile, the Thermite and the Toucan) in order to reduce its environmental when in use (see figure 2).

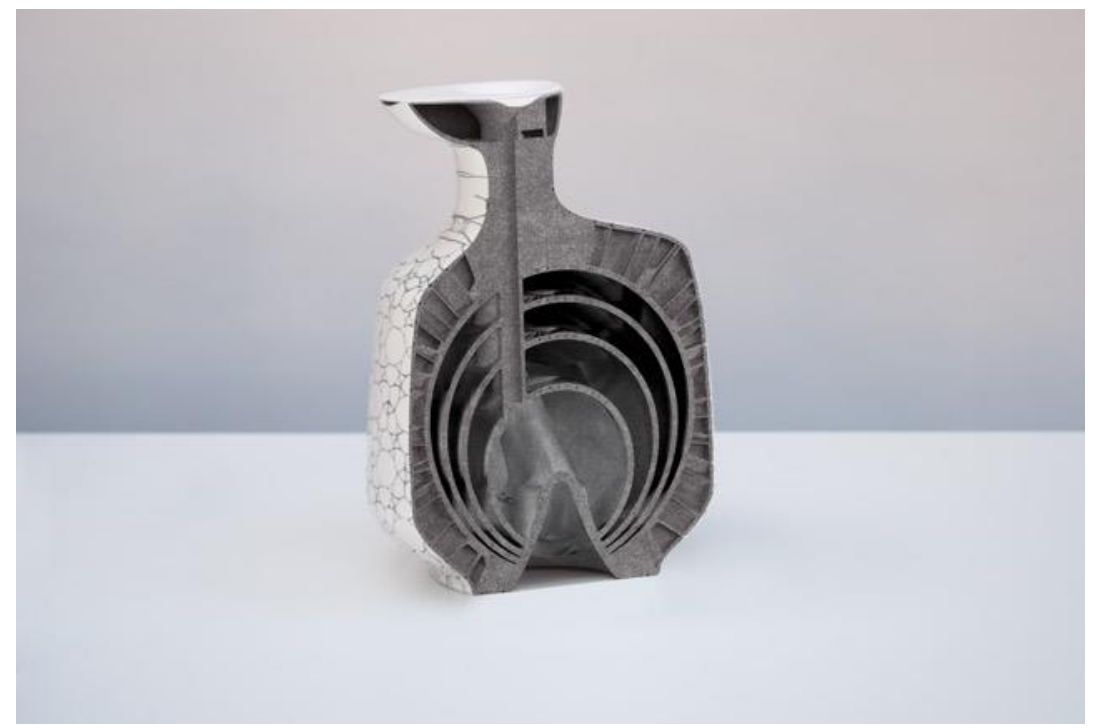

Figure 2: Nautile kettle, 2012, by Designer Guillian Graves and bio-engineer Michka Melo 
Acknowledging the biological advantage in terms of sustainable material fabrication and shape forming processes can also challenge the very notion of what we define as smart materials as demonstrated by Dr. Jane Scott who developed an innovative bio-inspired dynamic knitted fabric system. Referencing the pine cone and exploiting the inherent characteristics of plant based fibres, Scott engineered a series of $100 \%$ natural knitted textiles that dynamically respond to a rise in humidity level. Figure $3 a$ and $3 b$ show the same fabric before and after being sprayed with a mist of water at ambient temperature. The actuation and shape-change is a direct result of the structuring of the material itself. Scott | (2015). This innovative textile project demonstrates that we can design and engineer dynamic responsive materials without the use of artificial polymers or electronics and sets a new benchmark for bio-inspired future smart textiles.

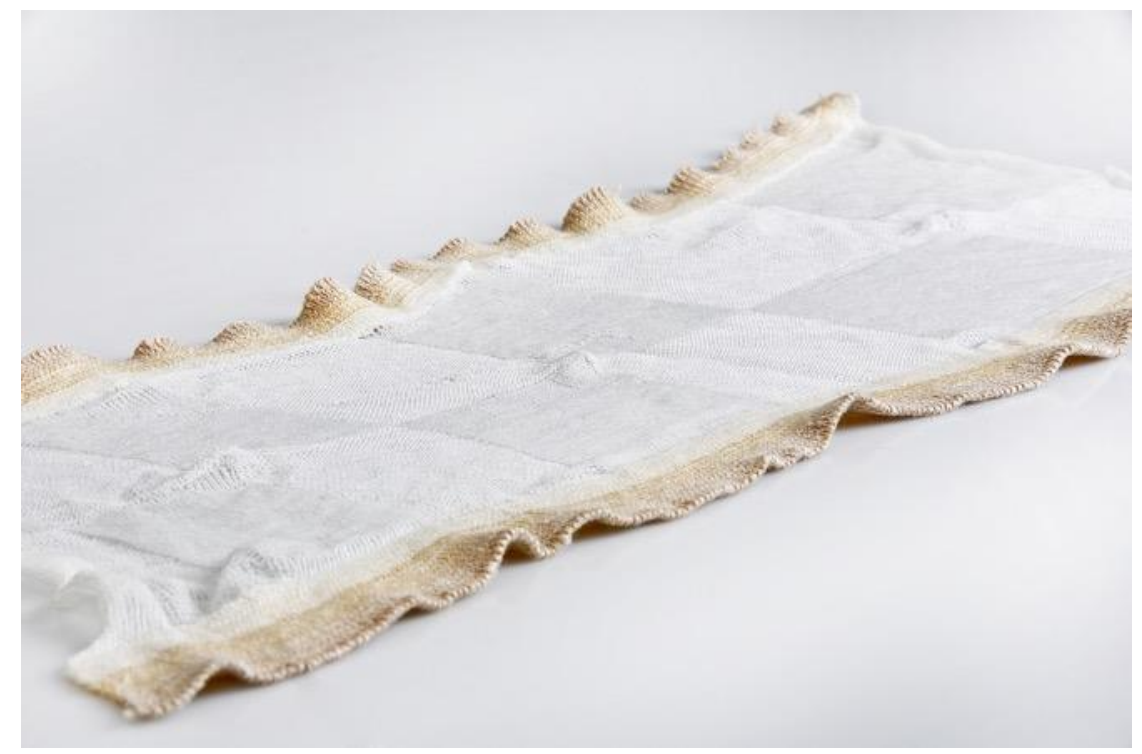

Figure 3a: Colonise, Before actuation. (C Jane Scott. Photography by Cristina Schek

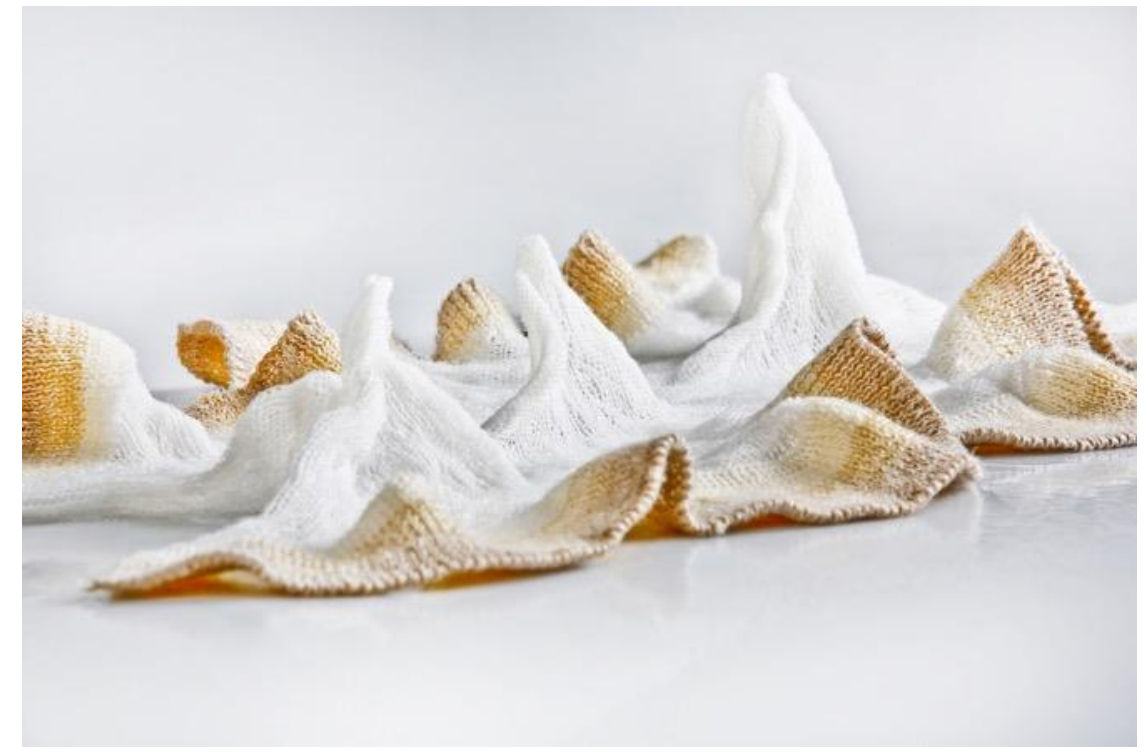

Figure 3b: Colonise, after actuation. (C) Jane Scott. Photography by Cristina Schek

As biomimicry is influencing a new generation of designers and architects, it is allowing for the language of biology to be incorporated within the design development. And the closer 
we get to how a natural model works, the more the temptation to actually biofabricate like Nature does. So whilst some designers refer to biomimicry as a means to study and replicate a behavior, a system or a pattern, others attempt to integrate biological functions into the design process. This range of approaches brings to question designers' relationship to the natural world, as it resonates with both a mechanist interpretation of nature and a more holistic and cooperative one. The following section posits a framework for designing with the living that creates a hierarchy of design interventions with the Natural world and helps navigating this emerging biodesign landscape.

\section{A Framework for Designing with the Living}

The premises for this framework (Figure 4) were established when I began preparing the curatorial work for the exhibition 'Alive, New Design Frontiers' with the EDF Foundation in 2013 and have since informed the developmental work of the Design \& Living Systems Lab at Central Saint Martins, University of the Arts based in London. As an educationalist, a researcher and a designer, I started exploring biology as a potential tool for sustainable design in 2007. Whilst I was evolving new design and educational methods fit for this purpose, I witnessed the rapid emergence of a new breed of designers and architects that were equally seeking to incorporate biological principles within their design process; some did so in pursuit of a sustainable goal, others were simply driven by the novelty factor. Mapping this new biodesign landscape became a necessity to develop a critical stance, in particular when examining the ethics of designing with synthetic biology (which will be discussed in section four) and the potential for biodesign to foster a more sustainable practice.

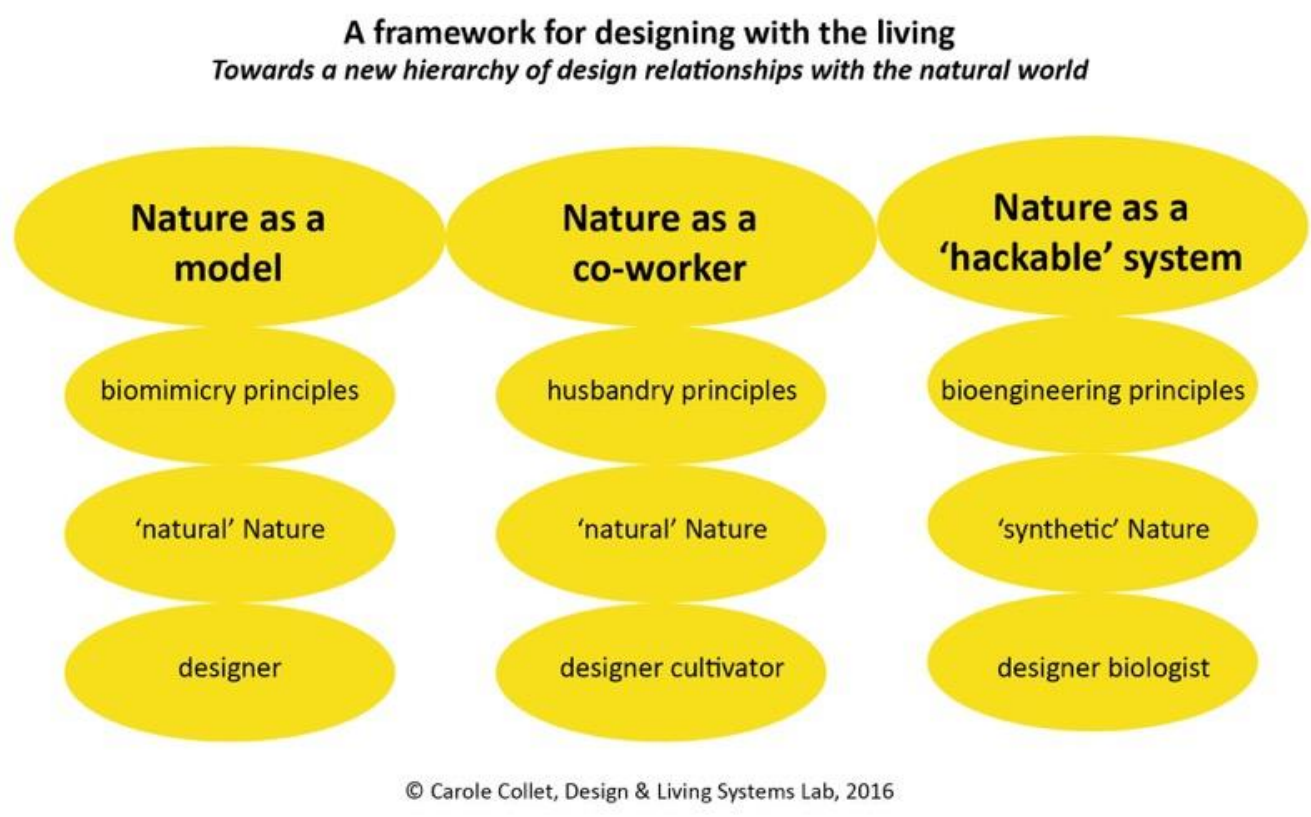

Figure 4: ㅇ Carole Collet, Design \& Living Systems Lab 2016.

The framework proposes a hierarchy in three folds:

1. Nature as a model: The most conventional of the three, this is where designers explore biomimicry principles to imitate a behavior, a function or a pattern, as seen in section three above. 
2. Nature as a co-worker: This category combines biomimicry approaches together with husbandry techniques. Here the designer becomes a cultivator who grows and controls the morphology of materials by collaborating and cooperating with natural organisms such as bacteria, fungi or algae as will be discussed in section five.

3. Nature as a 'hackable' system: This is the most recent approach, only possible since the advances of synthetic biology which allows for the bespoke genetic engineering of simple living organisms, redesigned to produce tailored and tunable substances. Bacteria can be reprogrammed to produce biofuel, yeast to grow vanilla and silk. As designers embrace or rebel against these new biotechnological possibilities, a new array of design propositions have emerged and will be discussed in section six.

This proposed framework is profoundly anchored within our changing cultural perception of the natural world. As we have discussed previously, we have historically shifted back and forth from a holistic to a mechanistic reading of our natural environment. The three categories of this framework highlight a divergence of position. Nature as a model proposes to acknowledge the supremacy of solutions that have evolved over 3.8 billion years and their ecological advantage. Co-working with Nature endorses values of cooperation and partnership, whilst 'hacking' natural systems fosters values of control and dominance inherent to the $20^{\text {th }}$ century idea of Nature as an exploitable limitless commodity. Designers can shift from one category to the other, but in doing so they need to assess their perception of the living and evaluate their ethical stance in the context of growing a more sustainable world.

The following two sections will reference this framework by examining more specifically design propositions arising from the second and third category: the 'designer cultivator' and the 'designer biologist'.

\section{Co-working with living organisms: the designer cultivator}

The late physicist Richard Feynman once said, 'what I can not create, I do not understand' Feynman | (1988). Here it is more appropriate to argue that what I can not grow, I can not understand. To establish a co-working partnership with a living organism, designers need to provide a suitable environment of growth. In return, the living organism will generate a material or perform a function. This design approach entails understanding the mechanics of growth, and a new set of tools and methodology for design. Instead of working in relation to existing pre-manufactured materials, designers can now cultivate their own materials, and in doing so affect their morphology and plasticity as they grow. In 2003, fashion futurist Suzanne Lee pioneered this model when she developed BioCouture, a fashion range that explored 'the use of living cultures of microorganisms (yeast and bacteria) to grow biomaterials like cellulose into sustainable, compostable clothing' Lee | (2013: 19). Kombucha is a traditional fermented drink made with tea, sugar, bacteria and yeast. As the bacteria and yeast develop and ferment, they release a cellulosic material that rises to the surface. Revisiting the Kombucha recipe, Lee established a research protocol to harness bacterial cellulosic material and produce a leather-like range of fabrics. BioCouture triggered a fundamental shift in textile and fashion research and has become a point of reference in the field of biodesign. In 2013, Lee, in collaboration with Liz Ciokajlo- 
Squire produced BioCouture Shoe, the first 'grown' shoe exhibited in 'Alive, New Design Frontiers', EDF Foundation (see Figure 5).

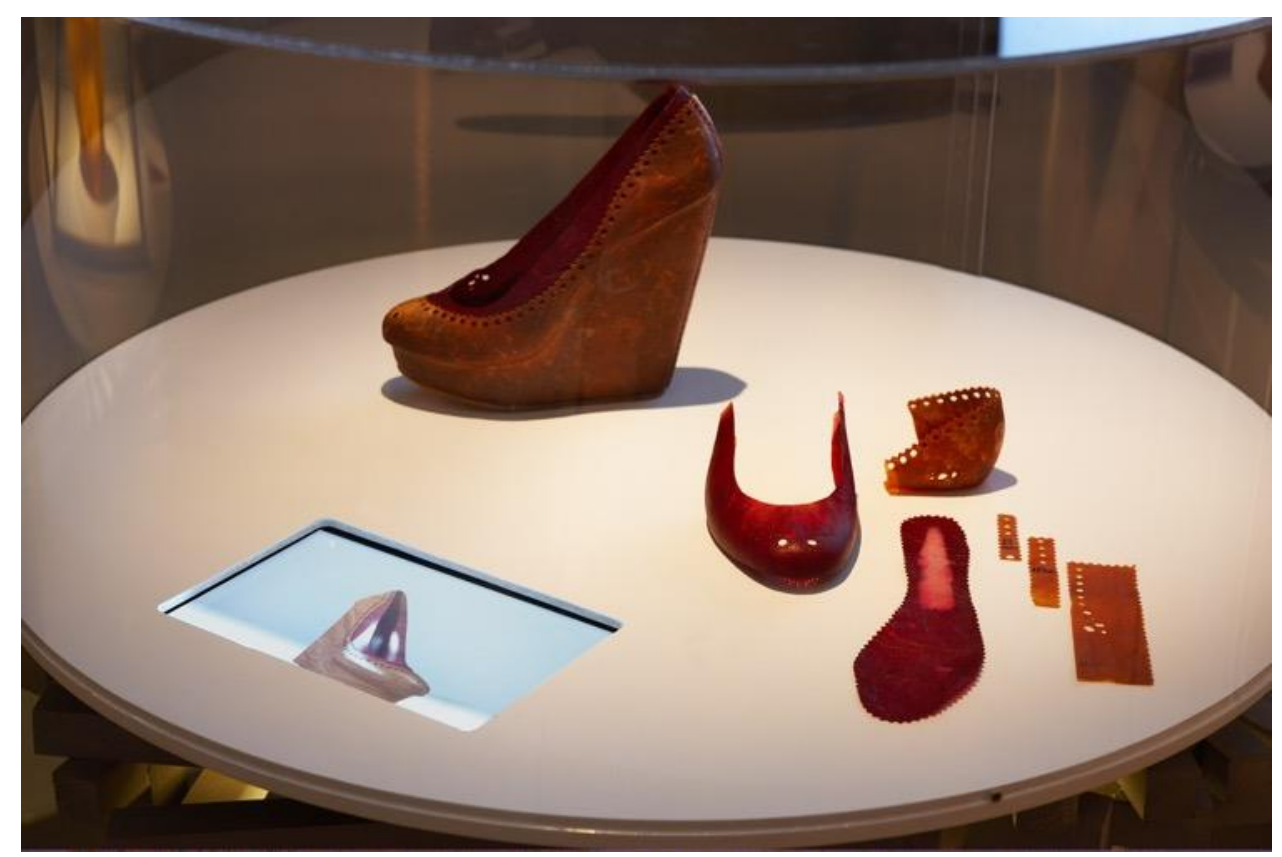

Figure 5: BioCouture Shoe, presented at Alive, New Design Frontiers, EDF Foundation, Paris, 2013. (C) Suzanne Lee. Photography Laurent Lecat / EDF Foundation.

As demonstrated by Lee with the bacterial-grown shoe, the developmental morphogenesis of a material can become a site for design intervention. The control of growth as a shapeforming technique is particularly relevant to design researchers working with mycelium. An early innovator in this field is artist Phil Ross who 'started from a desire to understand how environmental conditions influence the aesthetics of life forms' Ross | (2016: 252). Vegetative bodies of fungal mycelia can reach enormous size making it the largest organisms on Earth and form an integral constituent of healthy soil, allowing trees to develop underground symbiotic networks to exchange nutrients. We have only recently begun to understand the potential of this organism in terms of sustainable design applications. 'Fungi are the grand recyclers of our planet, the mycomagicians disassembling large organic molecules into simpler forms.' Stamets | (2005: 1). Ross is exploring co-design techniques with mycelium to grow new kinds of biodegradable and compostable materials in preformed moulds. This includes mycelium bricks, furniture as well as architectural materials grown on waste streams (see Figure 6). 


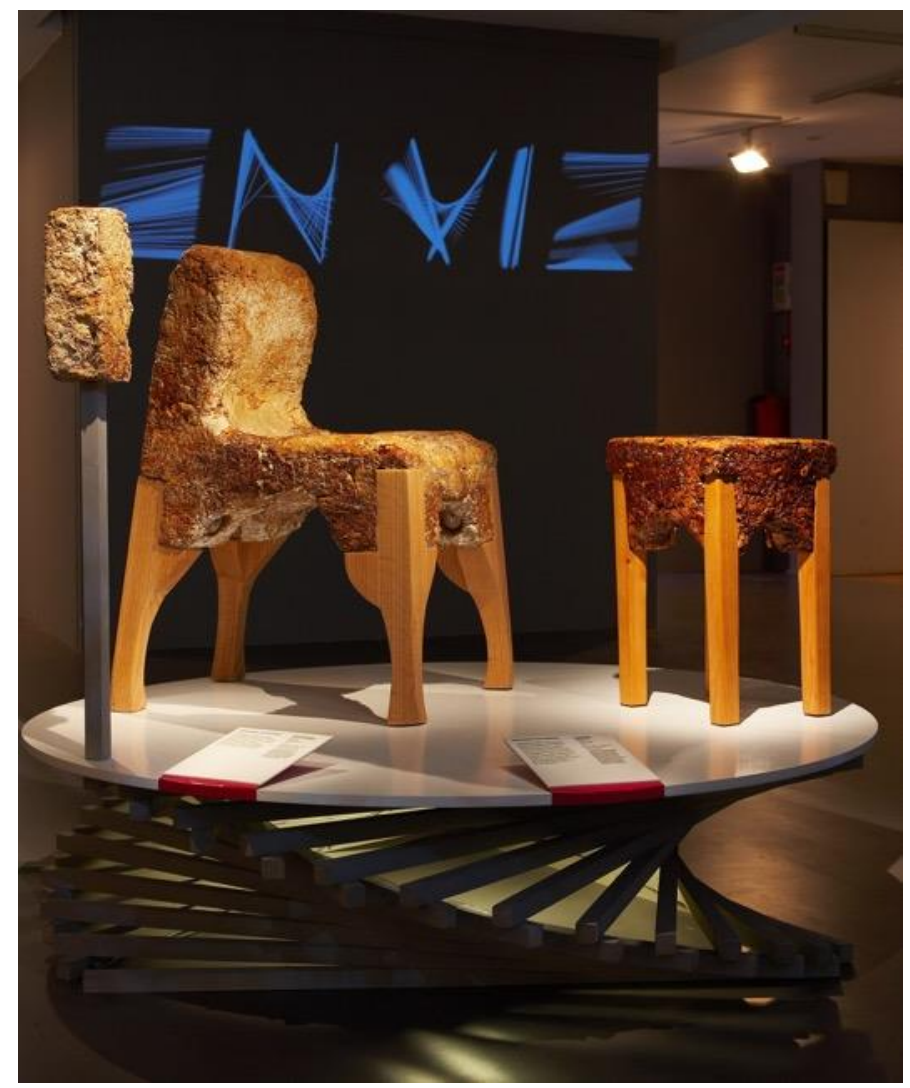

Figure 6: Yamanaka furniture and Micotecture Brick, Presented at Alive, New Design Frontiers, EDF Foundation, Paris, 2013. (c) Phil Ross. Photography Laurent Lecat / EDF Foundation.

In 2015, I became particularly interested in exploring a partnership with mycelium to develop sustainable patterning and finishing techniques for textiles. But in addition to controlling the growth environment through variations in the substrates and the geometries of the moulds, I also wanted to encourage a form of self-expression. I therefore developed a protocol that provides the right conditions for mycelium to grow, but allows it to manifest its self-organised behavior in the form of visible patterns. As seen in Figures 7 and 8 , the patterns, reminiscent of floral design are actually produced by the mycelium itself, rather than being shaped by a mould. Here I have designed the conditions of growth, provided care, food and warmth, but the mycelium created the pattern. In a conventional textile design context, a designer would start working with a given fabric material and apply various techniques such as screen printing or laser cutting to create a set of pattern according to a chosen aesthetic. Here the morphogenesis of the material as it grows simultaneously triggers the appearance of patterns and defines the final aesthetic of the sample. So who is the designer? In this instance the role of design is more akin to husbandry principles and gardening practices, and manufacturing becomes 'horticulturing'. 


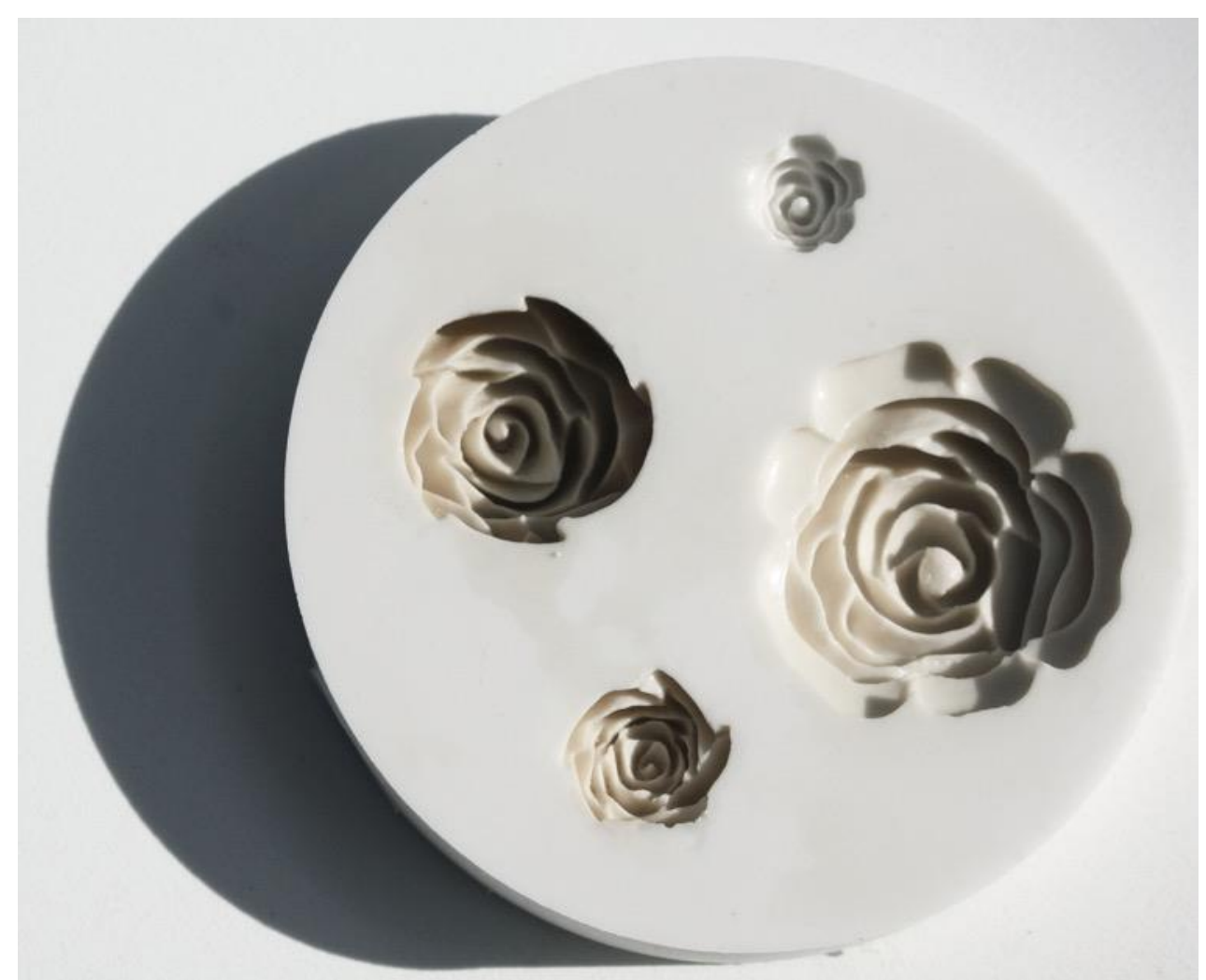

Figure 7: Mycelium Rubber: Mycelium grown on coffee waste, Details of self-organised floral patterns @ C Carole Collet 2016

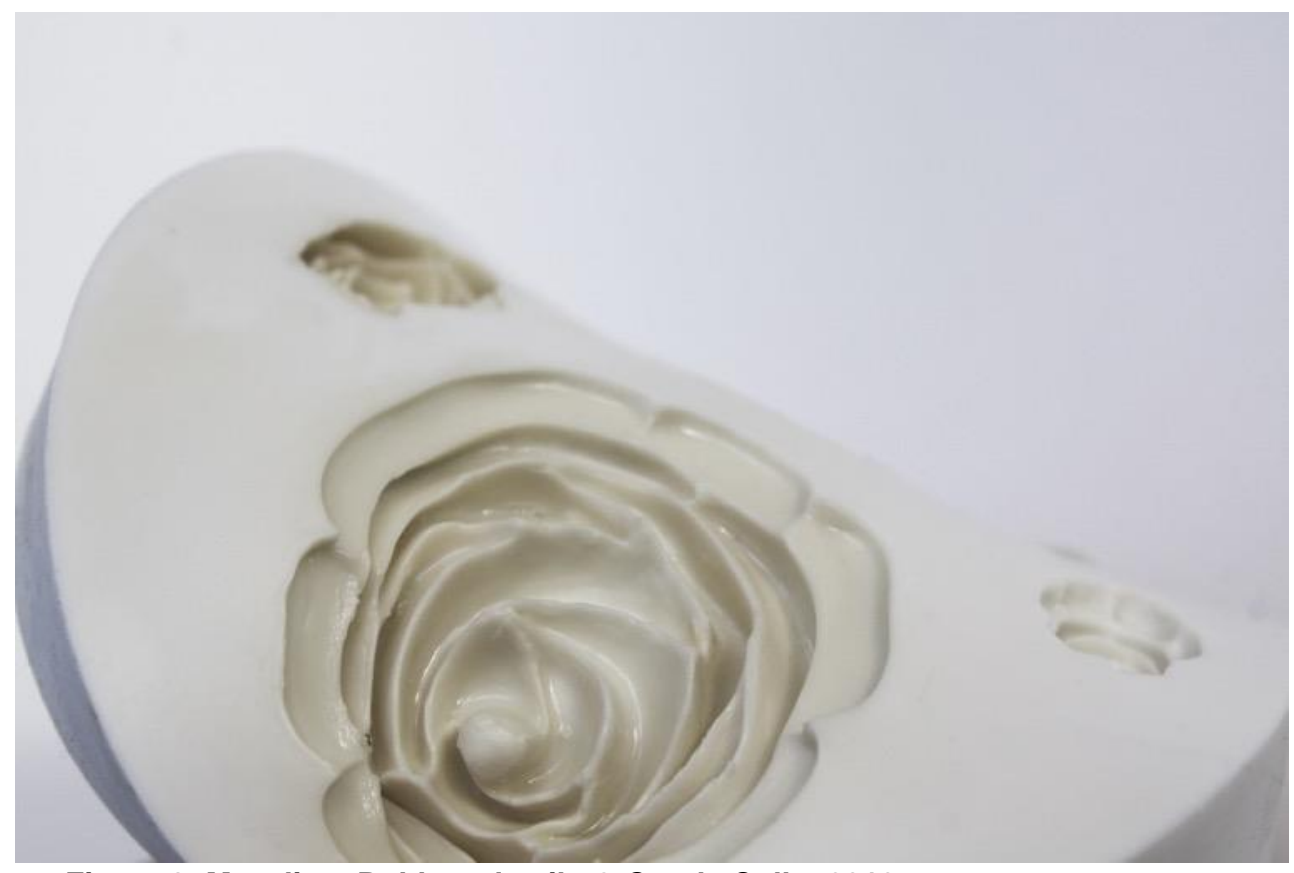

Figure 8: Mycelium Rubber, details @ C Carole Collet 2016

This emergent biodesign practice is radically altering the traditional skillset required of designers, and is proposing a new alternative for sustainable material production which harvest the inherent qualities of living systems. The Mycelium Rubber featured above is produced by encouraging a mycelium culture to grow on coffee waste; it is washable, biodegradable and compostable. The exploration of such design and biofabrication methods contributes to develop new material propositions to shift towards a more 
sustainable circular economy. Whilst the development of new materials has predominantly been the remits of engineers and material scientists, designers are now expanding their roles from shaping existing materials, to creating and growing new ones.

On a different level, designer and researcher Amy Congdon also cultivates the relationship between form and directional growth in her $\mathrm{PhD}$ research project on the intersection of craft, textiles and tissue engineering. Congdon is devising micro scale textile architectures that encourage cell adhesion and cell growth. Her design research amalgamates tissue engineering laboratory protocols, textile embroidery skills and design making as she works across two specialist's research departments: the Design \& Living Systems Lab at Central Saint Martins University of the Arts, and Professor Lucy Di Silvio's department of Tissue Engineering at King's College in London. Using a range of fibres, Congdon crafts textile scaffolds that become the host for mammal cell development. In doing so she exploits both textile craft knowledge and scientific methods. Each iteration of a new textile scaffold provides new knowledge about the control of cell orientation and cell growth. Figure 9 shows the making of the scaffold, and Figure 10 shows a microscopic view of cell adhesion onto a fibre.

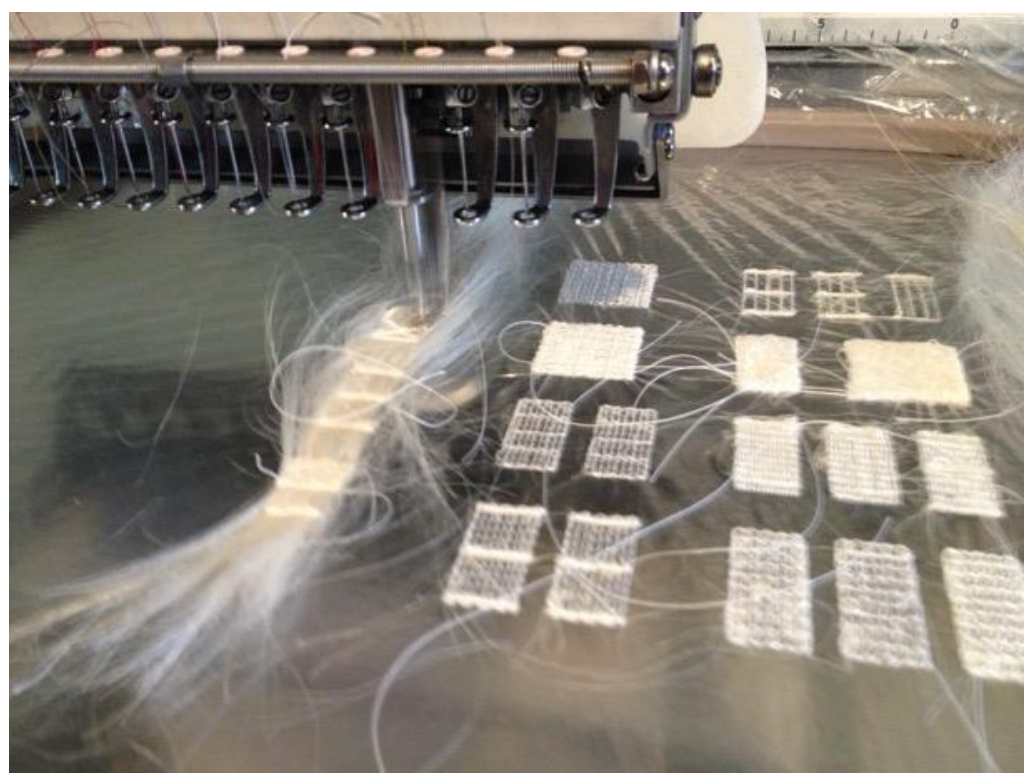

Figure 9: Embroidering scaffolds.

Tissue Engineered Textiles (c) Amy Congdon 


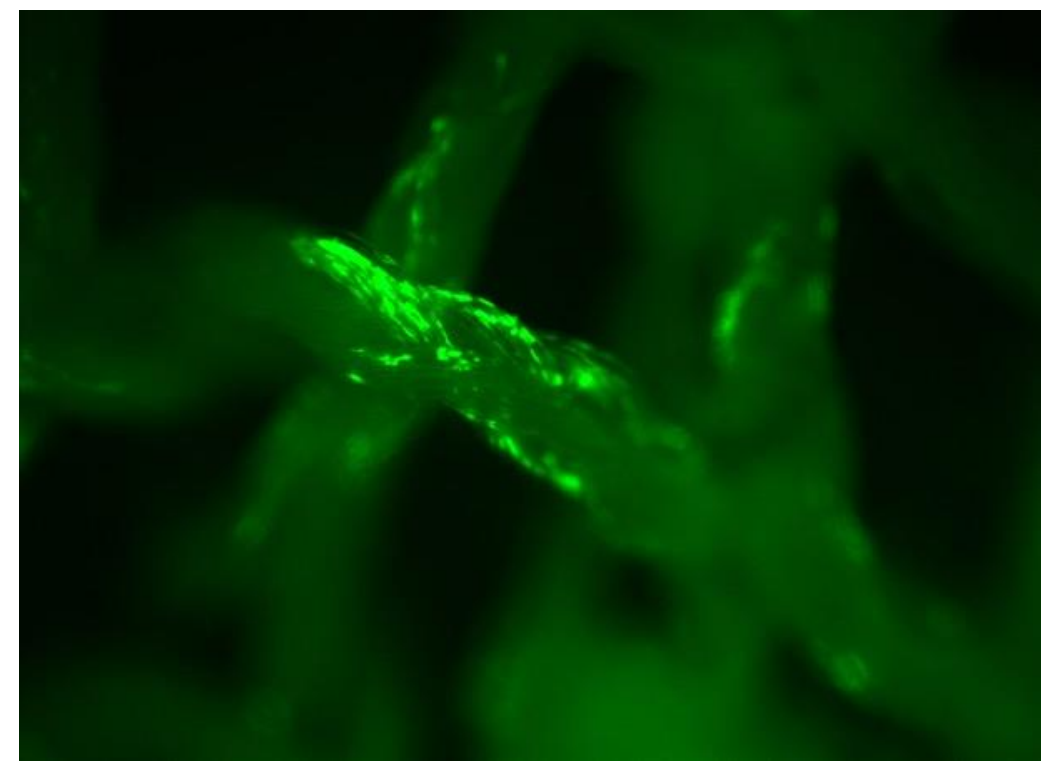

Figure 10: evidence of cell adhesion (fluorescent green) x 40 magnifications. Tissue Engineered Textiles (C) Amy Congdon

This use of scaffold is integral to the field of tissue engineering and is not new in itself.

Where Congdon innovates is in developing an iterative methodology whereby textile craft informs scientific protocols. This is particularly evidenced in the redesign of the petri dish, tailored to increase the life-conducive architectural potential of the scaffold when seeded with live cells. The petri dish pictured below (figure 11) is designed to hold a lightweight textile scaffold in the growth medium to remove any potential for displacement, thus optimizing cell growth.

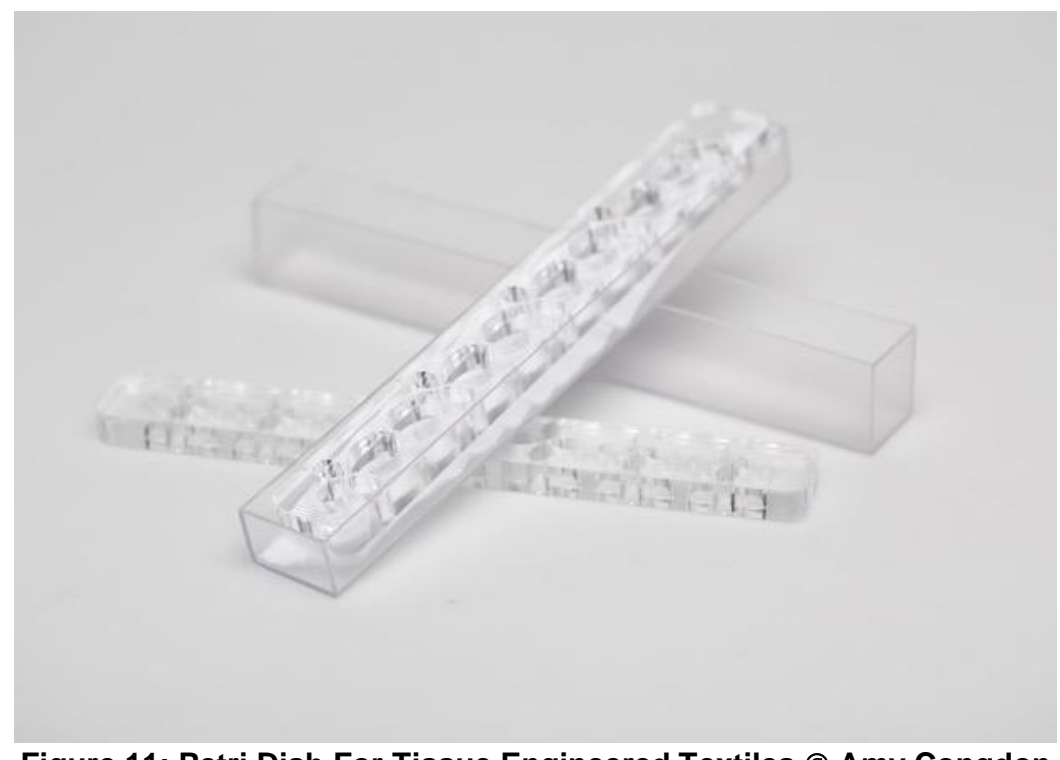

Figure 11: Petri Dish For Tissue Engineered Textiles @ Amy Congdon

With this project, Congdon contributes to knowledge in the field of tissue engineering and regenerative medicine as much as she if reforming methodologies for design. But as she is actively growing a mammal cell based semi-living entity, she is also questioning alternative possibilities for a new tissue-engineered materiality. Although not technically collaborating with a living organism as such, but rather with cells extracted from a living organism, Congdon manifests the expanded boundaries of design when co-creating with the living. 
She creates an environment of growth where she can cultivate and craft dynamic interactions between living and non-living matter.

In this section we have seen examples of 'designer cultivators' who interact with living organisms to create new biomaterials that harness the living dynamic qualities of life. This design approach manifests a shift from manufacture to biofacture, whereby living organisms such as bacteria and mycelium become the production chain responsible for the process of transformation. When design skills are augmented by a set of 'husbandry' techniques, we can engender a new form of bio-materiality that informs our sustainable futures.

\section{Hacking Living Systems: The Designer Biologist}

The search for innovative and alternative ecological design and manufacturing propositions is an integral part of our ability to transition to a sustainable future. In this quest, technology plays a pivotal role. And today, an emerging biotechnology is promising just that: synthetic biology is about to revolutionise the way we create matter, engineer functions and design future materials. New alternative products derived from the biofacturing power of biology are now being commercialised. Synthetic biology is defined by the Royal Society as 'The design and construction of novel artificial pathways, organisms and devises or the redesign of existing natural biological systems'. The Royal Society | (2016). Its applications range from biofuel to medicine, bioremediation and renewable biomaterials. This radical new scientific proposition enables us to produce natural materials using engineered living organisms remote from any natural ecosystems. Instead of imitating a natural system, we can fabricate like one, through bespoke tailored designed organisms. In 2012, UK chancellor Gorge Osbourne, announced that synthetic biology would become one of the eight key strategic technologies for the future economic growth of the UK Osbourne | (2012). This was further endorsed in a recently published strategic plan: 'Synthetic biology may provide the 21st century 'platform technology' required to create new industrial processes capable of producing and using a wider range of bio-based feedstocks, generating a greater diversity of products, and supporting the expanding bioeconomy with innovative solutions' SBLC | (2016:6).

Although effectively a form of extreme genetic engineering, synthetic biology is paradoxally often referred to as a potential future sustainable technology, both by public organisations and manufacturers. This is a complex issue. 'In many ways synthetic biology presents a dilemma; it may propose solutions to some of the greatest challenges facing the environment, such as climate change and scarcity of clean water, but also poses a high risk for natural ecosystems. The introduction of novel, synthetic organisms may therefore have both constructive and destructive effects on the conservation and sustainable use of biodiversity.' European Commission | (2016:13). Whilst technically synthetic biology can offer viable alternative environmental solutions, such as bioremediation of toxic soils, or the production of bio synthetic medicinal substances that do not require extraction from plants and animals, thus reducing our exploitation of wild habitat, it can also pose risks when it is scaled up from scientific research to large scale manufacturing.

In 2010, I produced a speculative design project to interrogate the potential of synthetic biology for future textiles and begin to question the sustainable implications of this emerging technology. The textile industry is a major polluter and is currently 'fourth in the ranking of product category which cause the greatest environmental impact, just after food \& drinks, transport and housing' EU Retail Forum for Sustainability | (2011: 1). With a 
population predicted to reach nine billion or more in 2050, researching new models for sustainable textile production and consumption is critical. In this context, the BioLace project posed the following questions: Can synthetic biology become a potential sustainable technology for future textile manufacturing? Will crafting molecules become a new way to produce fibres?' Collet | (2012:1). Biolace is a speculative fictional design project that explores the imaginary of synthetic biology to propose to engineer multifunctional plants for future urban hydroponic factories that would provide food and fabrics at the same time. With Strawberry Noir (Figure 12), one can harvest a strawberry augmented in anti-oxidants and vitamin $\mathrm{C}$ at the same time as picking black lace trimmings for the fashion market. Basil $N^{\circ} 5$ (Figure 13) provides culinary herbs and scented lace trimmings.

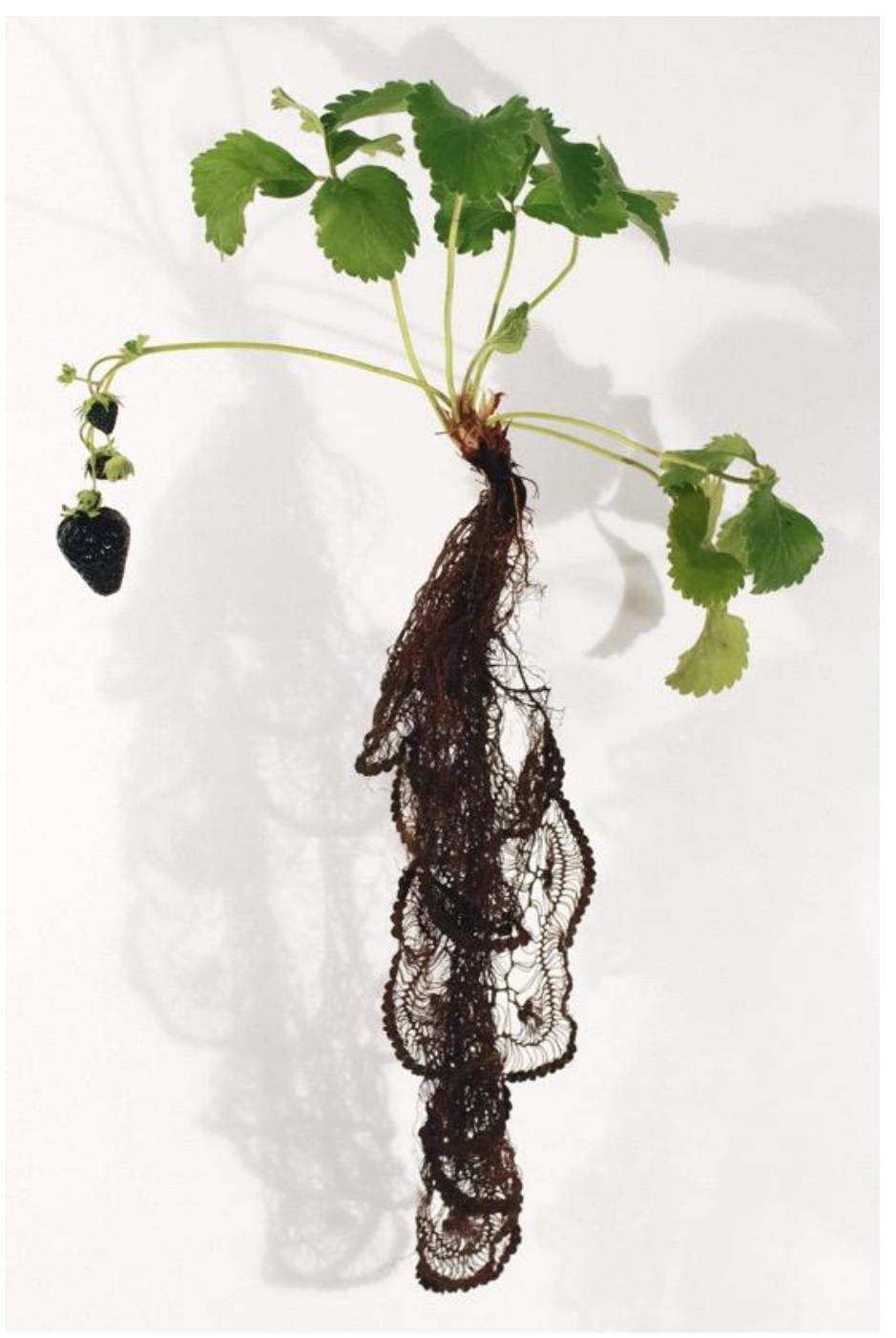

Figure 12: Strawberry Noir, (Fragaria Fusca Tenebris) (C) Carole Collet 


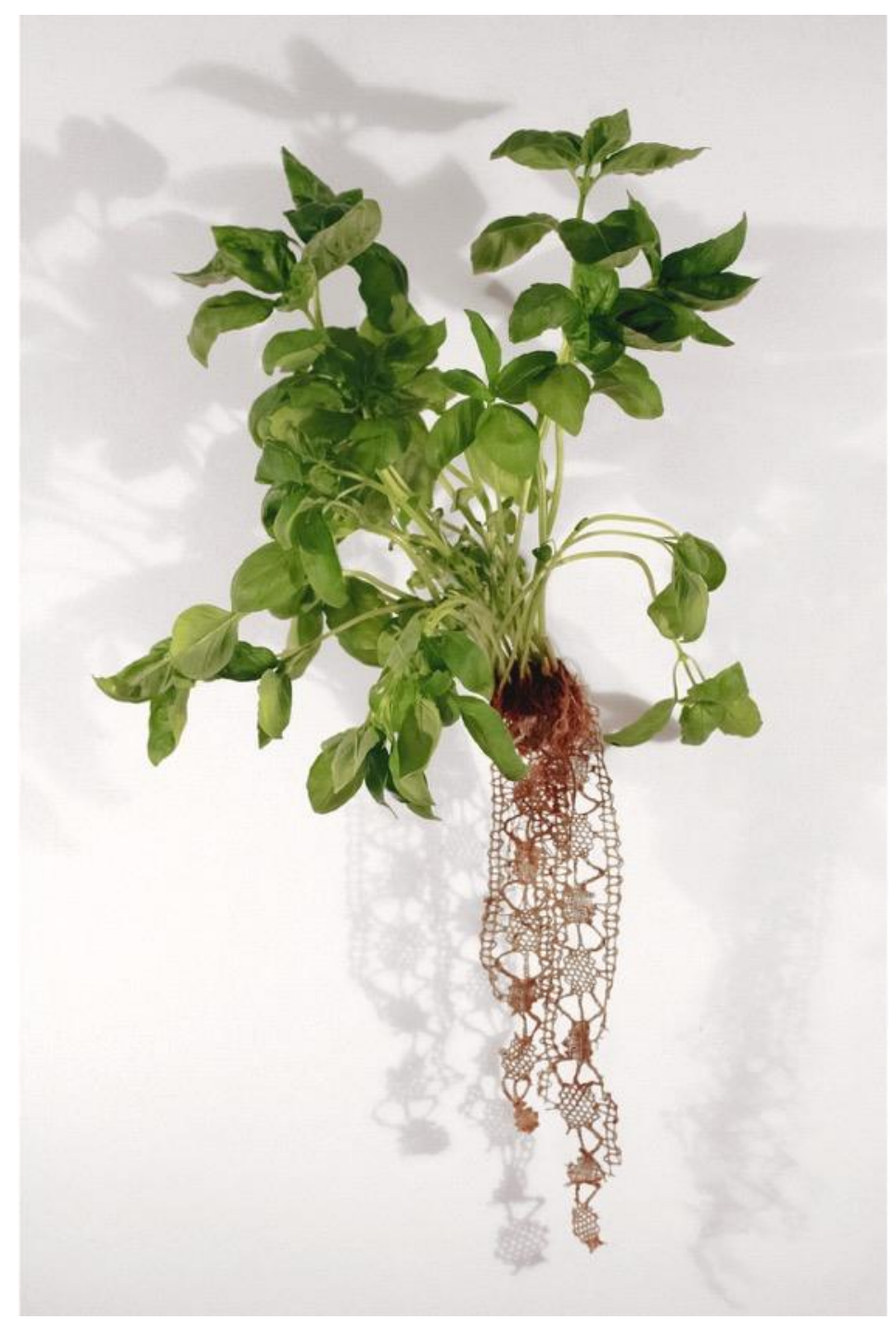

Figure 13: Basil №5 (Ocimum Basilicum Rosa) (C) Carole Collet

The Coconut tree and the Lagetta Lagetto tree (from Jamaica) both produce a bark very similar to a plain weave (see figures 14 and 15); the cotton plant grows fibres in a pod, and a mushroom known commonly as the 'veiled lady (Phallus indusiatus) grows a lace-like skirt.

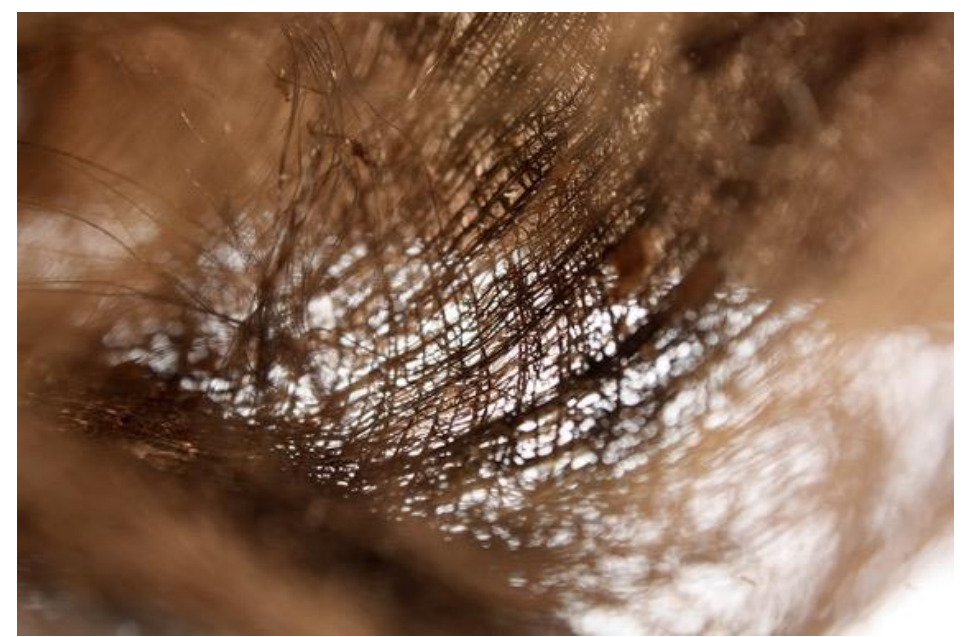

Figure 14: Detail of bark harvested from the coconut tree. Photograph Carole Collet. 


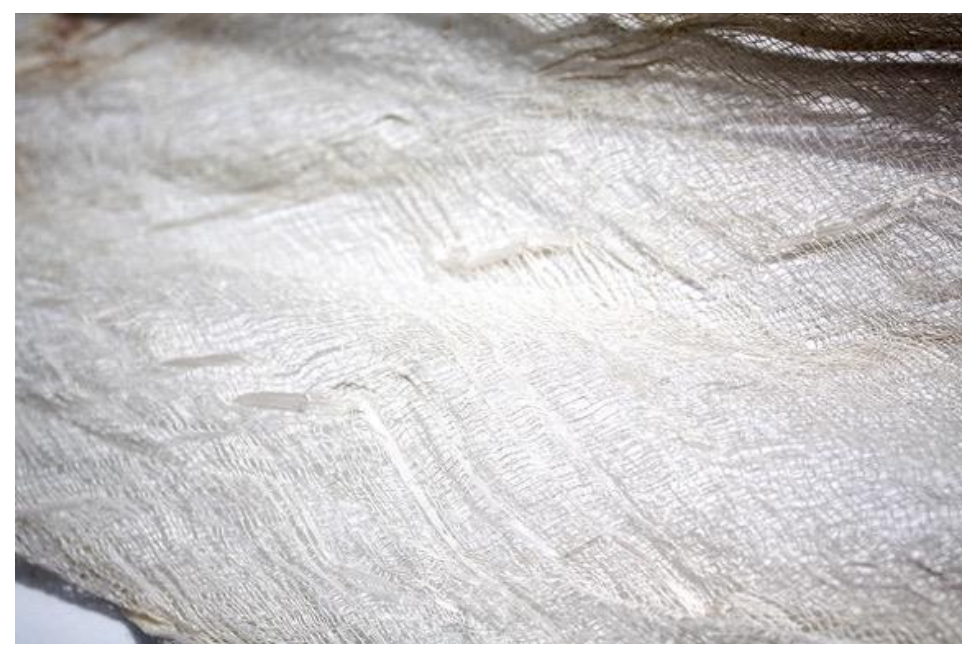

Figure 15: Detail of bark harvested from the Lagetta Lagetto tree in Jamaica. Photograph Carole Collet.

These examples illustrate that Nature provides solutions that could turn into future synthetic biology applications. These plants and trees contain a genetic code that is expressed in a constructed textile-like form, not just in a material or fibre form. Inspired by these natural models, Biolace proposes to use the tools of synthetic biology to revisit the morphogenesis of plant roots systems to create new functional neo-natural possibilities.

At the time of developing Biolace (2010 to 2012), the focus of the synthetic biology scientific community was primarily on exploring new means to biofabricate biofuels and medicine. Textiles were not a priority research area. Yet five years later, an array of new biotech starts up companies have catapulted the use of synthetic biology at the forefront of textile innovation. Bolt Threads has upscaled the production of synthetic silk grown by yeast (see figure 16) and partnered with Stella McCartney in 2017 to launch the first luxury synthetic fashion range, whilst Modern Meadow grows animal-free leather in a lab (see figure 17). 


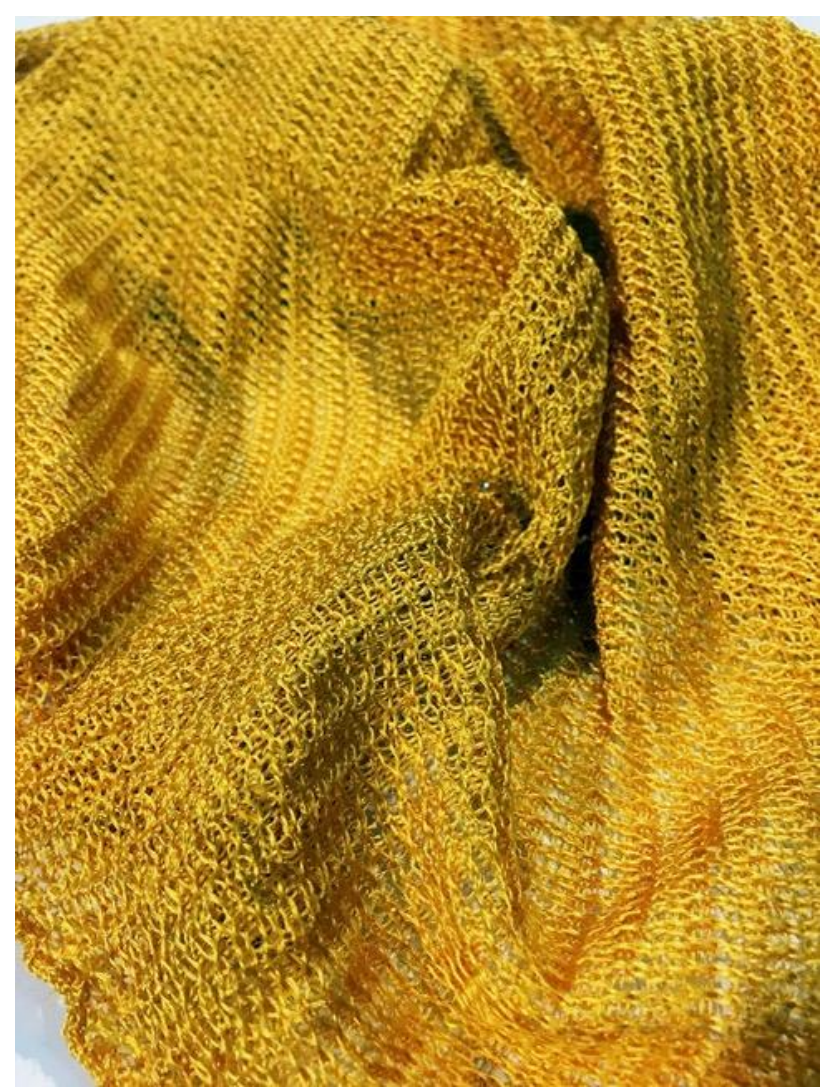

Figure 16: knitted silk produced by synthetic yeast, Bolt Threads. Exhibited at Biofabricate 2017. Photograph Carole Collet.

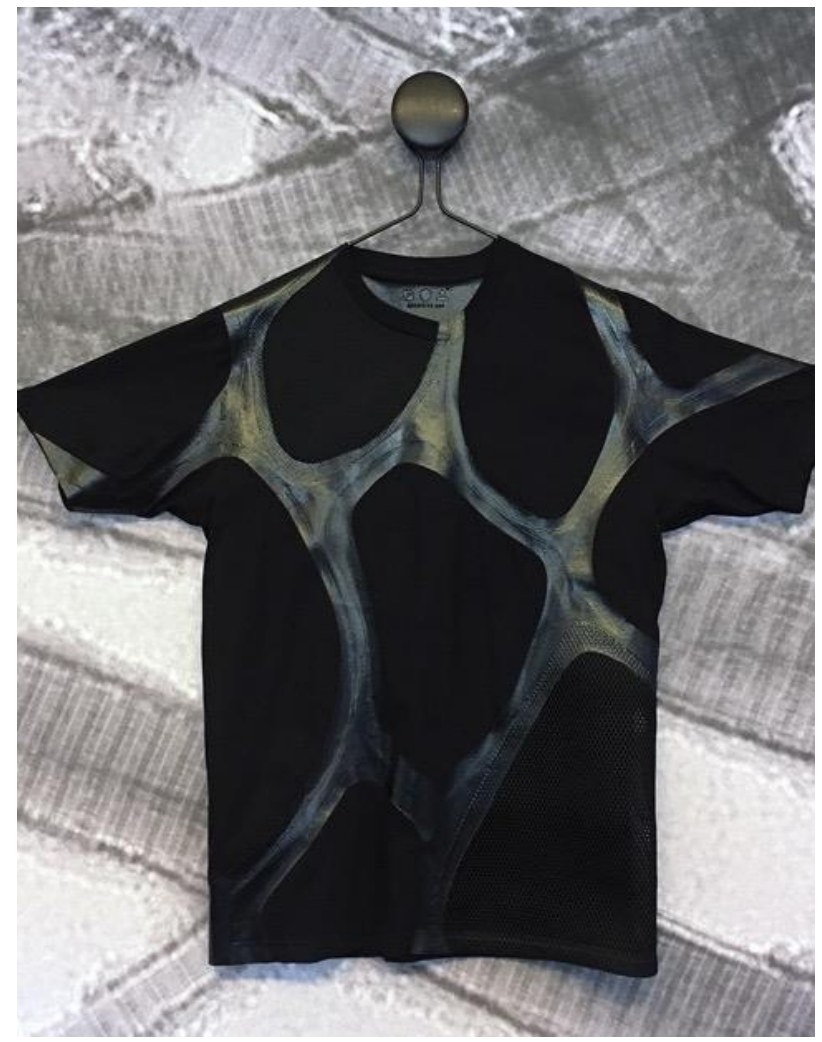

Figure 17: Grown of Zoa. Modern Meadow 2017.

T-Shirt patterned with liquid lab-grown leather, exhibited at Biofabricate 2017. Photograph Carole Collet. 
Both companies advertise their goals in terms of sustainable biofabrication that can revolutionise the traditional textile and fashion industry. What is particularly innovative is the possibility to tune the qualities of the material as it grows. Could we by-pass ecologically impactful finishing steps such as dyeing and surface coatings with this technology? It is still very early on to be able to assess the environmental implications of this biofabrication models, and their full life-cycle analysis would be required to do so. Yet a number of national policies have endorsed synthetic biology as a key leading sustainable technology: 'One of the most significant benefits of synthetic biology is considered to be the development of new methods and processes that enable industrial production in accordance with sustainable development and the replacement of fossil fuels'. Living Factories | (2017: 8). A definite advantage of synthetic biology it that it allows for the creation of biomaterials using microbes, bacterias or yeast which are programmed to feed on waste including $\mathrm{CO}$, or methane. Mango Materials, a US based start up, has recently launched a biodegradable biopolyester fiber made from waste biogas as a sustainable alternative to petroleum-based polyester.(http://mangomaterials.com).

As synthetic biology progresses new opportunities will arise, yet the role of the designer can be to develop a sustainable imaginary for this technology, one that is not driven by the technical prowess of synthetic biology, but rather inspired by environmental concerns. As such, the speculative design project 'Future Hybrids' (see Figures 18 and 19) continues to explore alternative synthetic biomaterialities for future textiles. Here I question the ethics of fur production and whether synthetic biology could enable us to grow fur without exploiting farmed animals or threatening endangered species. Future Hybrids considers a synthetic topology where the animal and vegetal worlds converge towards a new hybrid animate entity. In this case a mushroom and a plant are portrayed as reprogrammed to express the fur of an endangered raccoon.

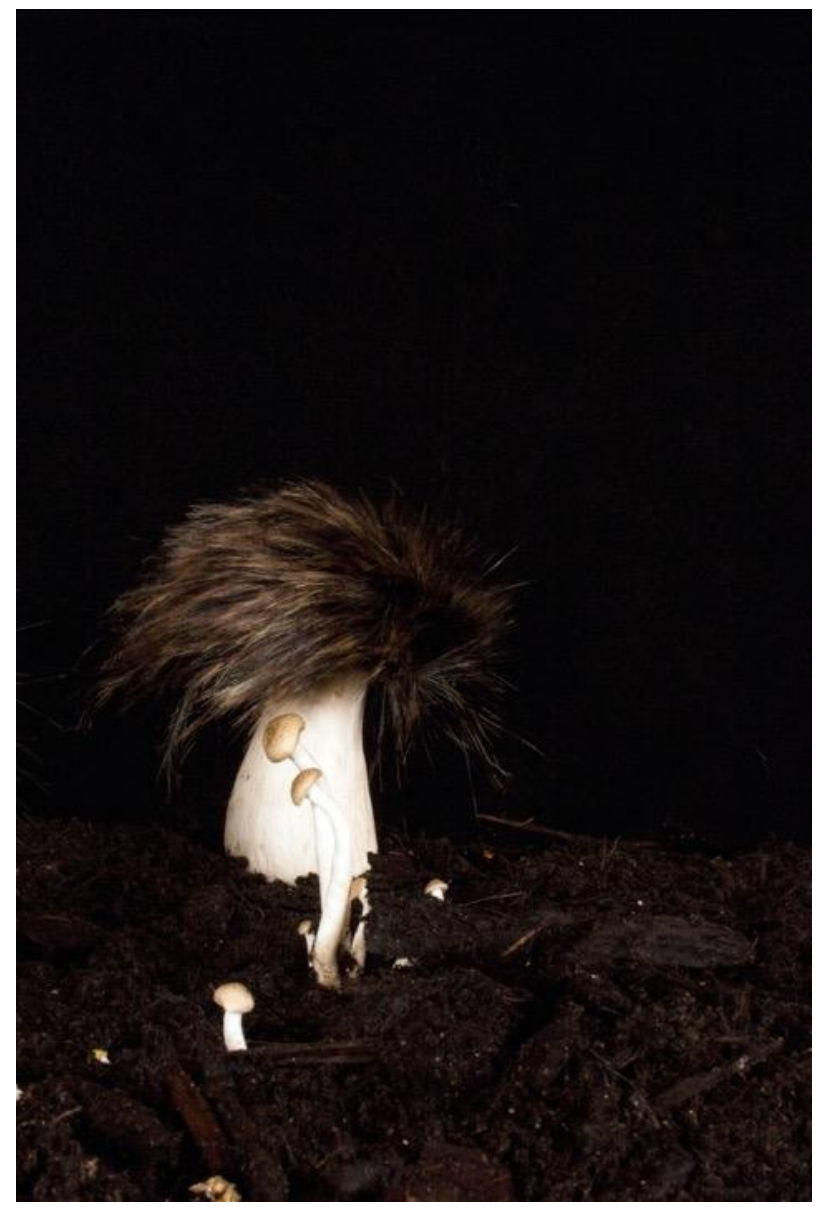


Figure 18: Raccoon Fungi, part of the Future Hybrid Series. Digital Print, 59 x 84 cm@ Carole Collet

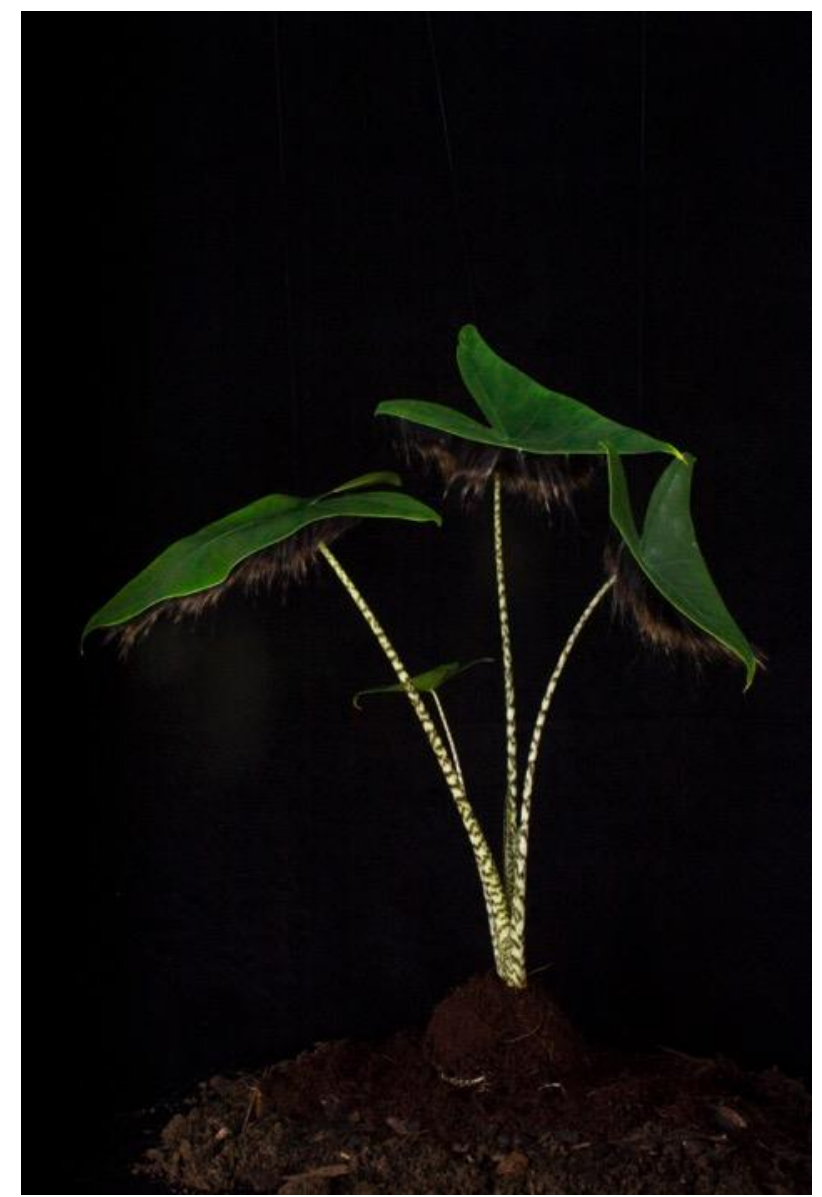

Figure 19: Raccoon Alocasia Zebrina part of the Future Hybrid Series. Digital Print, 59 x $84 \mathrm{~cm} \odot$ Carole Collet

Future Hybrids addresses the luxury market and suggests possibilities for animal free fur that could be further designed to embed brand values into seasonal fur. The notion of recombinant DNA, or the 'cut and paste' of genetic materials allows us to imagine hand picked characteristics of different species to be edited into new living hybrid material factories. Luxury brands could each develop furs that embed their aesthetic signature whilst being unique to each customer. This programmable new bio-luxury could integrate smart properties derived from natural organisms and develop new characterics to generate a new type of fur, inexistent in Nature. Above all, this project challenges the ethics of fur production and animal farming. Which is worse? A fur produced by killing a mink or a fungi reprogrammed to grow fur? In response to concerns of malpractice in fur farming, and on the basis of ethical grounds, a growing number of fashion houses are going fur free in their collection, with the most recent announcement made by Gucci in October 2017. Future Hybrids plays quite literally with the notion of gene editing as a means to provoke a new perspective of future fur and highlight the present means to produce natural fur. The next step however is not to pursue this metaphorical approach, but rather to develop lab-grown keratin in synthetic yeast which can then be harvested and processed into fur-like fabric using textile manufacturing technologies.

The ethical values and principles provoked by the manipulation of genetic materials are multifold. As the engineering of biology expands rapidly with vast private and public investments, the bioethical discourse seems less prominent than the seductive hype of this 
new technology. Whilst the precautionary principle should prevail, we are faced with legislation that differs from country to country and a technology that evolves faster than legal councils and ethical policy making can adapt. We need to monitor its further development and remain aware of the wider sustainable challenges. In this context, speculative and critical design can bring to light different perspectives and help test the future purpose and relevance of synthetic biology. 'Designers work the scene of technological emergence: they hack the present to create the conditions of the future' Balsamo quoted by Adams | (2014: 20). But to create these conditions, it is also vital that designers, who understand how to specify the use and performance of a material, engage proactively with scientists in the lab. Going beyond pure scientific breakthrough by enabling pertinent valid design applications will help shaping the future promises of this technology.

As we have seen in this section, actuating a new form of synthetic nature offers an expanded landscape for designers, one that will require a new skillset. iGEM, an international competition that fosters innovative pathways and applications for synthetic biology has become the de facto platform to encourage a far-reaching scoping of possible futures for synthetic biology. Originally driven by biology teams all over the world, iGEM is now strategically welcoming input from design teams, thus recognizing the value of design expertise within biological research. The 'designer biologist' as illustrated in this section has to integrate the language and technicity of biology as much as to understand the deeper ethical implications of crossing the divides between working with animate and inanimate matter. Whether using speculative and critical design or whether directly engaging with altering the materiality of living cells, it is crucial that designers engage with synthetic biology to help define and review the ethical and societal implications of such radical control over Nature.

\section{Conclusion}

This paper posits that designers have an expanded set of options to work with natural resources and as such contribute to shaping the Nature versus Culture debate. What is natural has become a blurred and shifting definition, very much challenged by the advances of synthetic biology. By establishing a set of hierarchies of design relationships with the natural world, it is possible to establish clearer design strategies that help position the role of the designer within future sustainable design research. Designing our future biomateriality may take us back to horticulture and husbandry traditions as much as it will arise from collaboration with cutting edge synthetic biology and tissue engineering research. But above all, ethics will have to take centre stage in the design discourse as the boundaries between the inanimate and the animate world converge.

\section{Acknowledgement}

With thanks to Central Saint Martins, University of the Arts for supporting the research of the Design \& Living Systems Lab and to the designers whose work is featured in this article.

\section{References}

Adams B | (2014) Crafting Capacities. In: S Yelavich, B Adams (eds) Design as Future Making. Bloomsbury 
Braungart M and MacDonaugh W | (2009). Cradle to Cradle. Remaking the Way We Make Things, Vintage

Capra F. Luigi Luisi P I (2014) The Systems View of Life, A unifying Vision. Cambridge University Press

Collet C | (2012) BioLace: An Exploration of the Potential of Synthetic Biology and Living Technology for Future Textiles in Studies in Material Thinking, Vol 07, Paper 02, ISSN 1177-6234AUT University. http://www.materialthinking.org

Crutzen PJ. Steffen W, McNeill JR | (2007). The Anthropocene: Are Humans Now Overwhelming the Great Forces of Nature? In Ambio Vol. 36, No. 8, December 2007, Royal Swedish Academy of Sciences 2007. https://www.pik-potsdam.de/news/publicevents/archiv/alter-net/former-ss/2007/05-09.2007/steffen/literature/ambi-36-0806_614_621.pdf (accessed September 2016)

European Commission, Retail Forum for Sustainability | (2011) Sustainability of Textiles. Issue Paper 11, August 2013.

http://ec.europa.eu/environment/industry/retail/pdf/issue_paper_textiles.pdf (accessed September 2016)

European Commission, Science for Environment policy | (2016). In Future Brief:

Synthetic biology and biodiversity issue 15, September 2016

Feynman R | (1988)

http://archives-dc.library.caltech.edu/islandora/object/ct1\%3A483 (accessed September 2016)

Lee S | (2013). In Alive, New Design Frontiers, exhibition catalogue, Carole Collet (ed). EDF Foundation

Livage J, Coradin T | (2008). Le verre biologique inspire les chimistes. In Pour La Science, N 371 September 2008. P.30-37

Living Factories | (2017) Synthetic biology as an enabler of sustainable bioeconomy - A roadmap for Finland

http://www.vtt.fi/inf/julkaisut/muut/2017/syntheticbiologyroadmap_eng.pdf (accessed February 2018)

Osbourne G | (2012). Speech by the Chancellor of the Exchequer, Rt Hon George Osborne MP, to the Royal Society, delivered 9th of November 2012 https://www.gov.uk/government/speeches/speech-by-the-chancellor-of-the-exchequer-rthon-george-osborne-mp-to-the-royal-society (accessed September 2016)

Pollan M | (2013). Cooked, A Natural History Of Transformation. Penguin Books

Pawlyn M | (2011). Using Nature 's Genius In Architecture. In TED talks, https://www.ted.com/talks/michael_pawlyn_using_nature_s_genius_in_architecture?langu age $=$ en (accessed September 2016) 
The Royal Society | https://royalsociety.org/topics-policy/projects/synthetic-biology/ (accessed September 2016)

SBLC - Synthetic Biology Leadership Council | (2016). Biodesign for the Bioeconomy, UK Synthetic Biology Strategic Plan 2016

https://connect.innovateuk.org/documents/2826135/31405930/BioDesign+for+the+Bioeco nomy+2016+DIGITAL+updated+21_03_2016.pdf/d0409f15-bad3-4f55-be03430bc7ab4e7e (accessed September 2016)

Scott J | (2015) Mutate: The Evolution of a Responsive Knit Design System. In: Proceedings of the 2nd Biennial Research Through Design Conference, 25-27 March 2015, Cambridge, UK, Article 5. DOI: 10.6084/m9.figshare.1327974. Available at http://researchthroughdesign.org/2015proceedings/

Stamets P | (2005). Mycelium Running, How Mushrooms Can Help Save The World. Ten Speed Press

United Nations | (2017). World Population Prospects The 2017 Revision Key Findings and Advance Tables

Wijkman A. Rockstrom J | (2012) Bankrupting Nature, Denying our Planetary Boundaries. Earthcan

WW | (2017) Living Planet Report 2016. Risk and Resilience in a new Era. WWF International, Gland, Switzerland 